\title{
The coming of the Crystal Mark
}

Some questions and answers regarding the Crystal Mark scheme introduced by the British 'Plain English Campaign' in 1990:

\section{What is the purpose of the Crystal Mark?}

The Crystal Mark symbolises clarity. It will chiefly appear on leaflets, brochures, forms, instructions, standard letters and legal documents including consumer contracts. The presence of the Crystal Mark shows that, in the opinion of Plain English Campaign, the document has reached a high standard of clarity in its language and layout. The Crystal Mark tells readers that the clarity of the document has been carefully examined by outside experts.

\section{What standards must be reached to obtain the Crystal Mark?}

Although the document must reach a high standard of clarity in its language and layout, precise yardsticks cannot be set. Plain English has been defined as 'writing that conveys its meaning clearly and concisely to the intended audience with the necessary impact and the appropriate tone of voice'. The document should also be well organised, logical and accurate.

We do not expect a document about a complex topic to be as easy to understand as one about a simple topic. In assessing a document we will try to consider the difficulty of the writing task and who the readers are likely to be.

Long sentences, too many passive verbs, unusual or pompous language and the absence of informative headings will all reduce the chance of the Crystal Mark being given.

Whether the finished document is typed or typeset, the type should be easily legible and the layout easy to follow. If different levels of heading are used, there should be a good reason for them and they should be clearly distinguished from each other.

Small, poor quality type, inadequate space between lines and excessive line length will

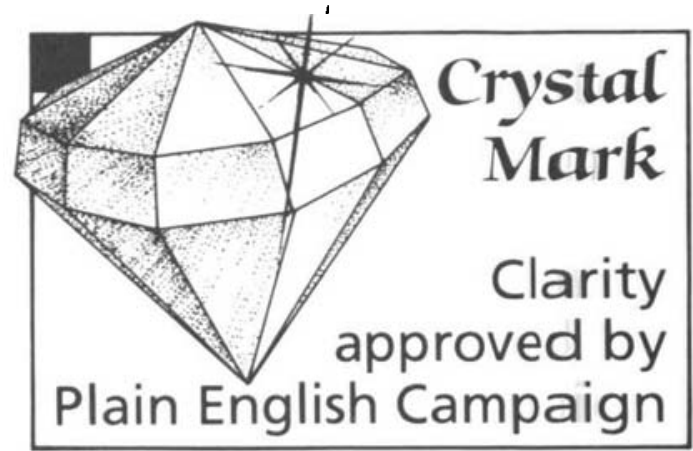

reduce the chance of the Crystal Mark being given.

Information about plain English and clear layout is given in Campaign publications and elsewhere. We can supply a reading list on request.

\section{Can Plain English Campaign help a document to reach the necessary standard?}

Yes, if you wish. We offer an editing, drafting and typography service which can suggest improvements. On the Crystal Mark entry form you can ask us for an estimate for the cost of any necessary work. But you are not obliged to consult us in this way, nor to accept our suggestions.

Who will decide whether to give the Crystal Mark?

A team of our most experienced writers and typographers. When necessary, we will consult other experts in various fields of communication.

\section{How may the Crystal Mark be used?}

The Crystal Mark should be printed on the document in one colour, either black or the darkest colour being used. If you wish to use a second colour on the Mark you must consult us first and get our written permission.

The minimum size for use of the Crystal Mark is $40 \mathrm{~mm} \times 26 \mathrm{~mm}$.

You can decide where on the document 
you use the Crystal Mark. We prefer the bottom of the back page, the front page or the inside front cover.

\section{May the Crystal Mark be used on other documents or on subsequent editions of the document?}

It may only be used on the document for which it is given. It is given specifically for the document, not for the organisation itself. You can use it freely on unchanged reprints of the document. If there are changes you should contact us for further approval; we may make a small charge for this check. Extensive changes may mean a completely fresh application for the Crystal Mark.

\section{What does using the Crystal Mark cost?}

We ask every organisation which receives permission to use the Crystal Mark to contribute to the costs of the scheme. The fee is $£ 500+$ VAT. There will be a reduction per document for a series or batch of documents.

\section{How do organizations obtain the Crystal Mark?}

Getting the Crystal Mark may take some time. There are five steps that any applicant should follow:

1. Fill in the entry form. Send it to us with the text of your document. Send anything else that will help us to understand what you are trying to achieve. You do not need to send a copy of the finished artwork at this stage.

2. Normally within 7 days we will give you a preliminary assessment of whether the document could qualify for the Crystal Mark. This will be on a standard checklist; it will indicate necessary improvements in general terms only.

If you have asked us on the entry form for an estimate of the cost of our making these improvements, we will provide one at the same time. You are free to accept or reject our suggested improvements.

3. You re-submit the text of the document with any comments you wish to make. If we have not already seen a copy of the finished artwork, we may need to see and approve a copy of it.

4. We will decide whether to offer the Crystal Mark and will let you know our

\section{Current Crystal Mark holders}

The following list of Crystal Mark holders was correct at the start of April 1991:

\section{Insurance companies}

\section{Eagle Star -2 policies}

Preferred Assurance - 1 policy

PPP MedicalCare - 1 policy

Provincial Insurance -3 policies,

2 information packs, 1 form

Prudential Assurance - 15 policies

Scottish Widows - 1 brochure

\section{Banks and building societies}

Abbey National -2 reports

\section{Electricity, gas and water companies}

British Gas -7 booklets, 1 bill

MANWEB - 215 letters

Wessex Water -2 bills

Yorkshire Electricity -2 forms, 5 letters, I bill

\section{Government departments}

DTI - 1 form

Lord Chancellor's Department - I leaflet

\section{Local authorities}

Bath City Council - 1 booklet

Derby City Council - I information pack

North Devon District Council - 1 form

Stirling District Council - 1 booklet

\section{Other organisations}

\section{Ciba-Geigy - 1 booklet}

Family Planning Association - 14 leaflets

IRPC Group Limited - I manual

Jordans Publishing - 1 information pack

Nottingham Community Housing

Association - I handbook

decision and any conditions.

5 . We will send you your uniquely numbered Crystal Mark as camera-ready artwork. We will invoice you for your contribution to the Crystal Mark scheme.

Further information from Plain English Campaign, Outram House, 15 Canal Street, Whaley Bridge, Stockport SK12 7LS, UK. 